\title{
Cellular Interrelationships During Laminar Segregation in the Dorsal Lateral Geniculate Nucleus
}

\author{
Judy K. Brunso-Bechtold and Sherry L. Vinsant \\ Department of Anatomy, Bowman Gray School of Medicine, Winston-Salem, North Carolina 27103
}

In order to gain insight into the mechanisms involved in the formation of groupings of functionally similar cells in the developing nervous system, we have studied the formation of cell layers in the developing dorsal lateral geniculate nucleus (dLGN). To examine the possibility that a higher affinity or adhesion between cells in individual layers may play a role in laminar segregation, we studied cellular interrelationships in the dLGN of tree shrews before (P0), during (P4 and P7), and just after (P15) laminar segregation has taken place. We compared our observations at these stages of development with similar observations in the adult. In none of the cases do we see evidence of gap junctions either between adjacent neurons or between neurons and processes in the surrounding neuropil. However, we frequently observe the presence of puncta adherentes between adjacent neurons at all stages of development. These profiles are also present between neurons and cellular processes in the neuropil. We also see subsurface cisternae in all of our cases, although these are more pronounced before and during interlaminar space formation. As with the puncta adherentes, these are found both between adjacent neurons as well as between neurons and other elements in the neuropil. We also see some evidence of what appear to be cytoplasmic bridges between adjacent neurons; these are quite rare but appear to be present only before and during laminar segregation. Finally, we frequently see cytoplasmic processes interdigitated between otherwise immediately adjacent cells. These processes also are often found oriented along other portions of the neuronal plasmalemma. Whether these processes are portions of neuronal growth cones or glial processes is impossible to determine at this time. Because of the potential role glial processes may play in the formation and maintenance of laminar cell groupings during layer formation, we have also made a preliminary survey of whether glial cells can be distinguished ultrastructurally at the stages we have studied.

Throughout the nervous system, functionally related cells are often segregated from the surrounding tissue. A particularly prominent example of such organization is in the visual system

\footnotetext{
Received Mar. 13, 1987; revised Nov. 9, 1987; accepted Nov. 11, 1987.

We gratefully acknowledge the excellent technical assistance of Constance Linville, the editorial comments of Dr. Ron Oppenheim and Keith Sutton, and manuscript preparation by Sarah Graham. Supported by EYO 5028 to J.B-B.

Correspondence should be addressed to Judy K. Brunso-Bechtold, Ph.D., Department of Anatomy, Bowman Gray School of Medicine, 300 South Hawthorne Road, Winston-Salem, NC 27103.

Copyright (C) 1988 Society for Neuroscience $0270-6474 / 88 / 082693-14 \$ 02.00 / 0$
}

of many species, in which cells in the dorsal lateral geniculate nucleus (dLGN) are arranged into distinct layers. These functionally distinct cell groupings, however, are not apparent at the time that dLGN cells migrate from their site of proliferation in the subventricular zone to their final location on the lateral surface of the developing diencephalon. Instead, in all species that have been studied, the dLGN cells initially comprise an undifferentiated cell mass that only secondarily segregates into the functionally distinct cell layers present in the adult (Rakic, 1977; Linden et al., 1981; Brunso-Bechtold and Casagrande, 1982; Cusik and Kaas, 1982; Shatz, 1983).

For some time we have been interested in the developmental mechanisms involved in the segregation of dLGN cell layers. Bilateral enucleation before the initiation of laminar segregation in both tree shrews and ferrets results in a subsequent failure of that segregation (Brunso-Bechtold and Casagrande, 1982; Guillery et al., 1985). The failure may be due to the absence of competition between the right and left eyes or to the simple absence of a major afferent input. In either case, there is a failure of the development mechanisms whereby the dLGN cells become physically segregated into layers. What those mechanisms are and how they are disrupted in bilateral enucleates remains unclear.

One possible means of laminar segregation in normal animals is that developing dendritic processes in adjacent layers and ingrowing axons and their synaptic terminals are most dense at the laminar borders, thereby pushing the layers apart. This hypothesis, however, is not supported by our quantitative assessment of the laminar and interlaminar distribution of growth cones and synapses during dLGN lamination, which was presented in the preceding paper (Brunso-Bechtold and Vinsant, 1988). An alternate hypothesis is that there may be a greater affinity or adhesion between cells destined to be in a given layer for each other than for cells in the adjacent layers. Such an affinity would permit the overall growth of the neuropil to result in groups of cells being segregated from each other as interlaminar spaces formed in regions of reduced affinity.

Our preliminary ultrastructural studies of the developing dLGN have revealed that prior to laminar segregation, ncurons are arranged in groups with considerable lengths of the plasmalemma of adjacent neurons in immediate contact (BrunsoBechtold and Casagrande, 1985). Accordingly, we undertook a study of these regions of cell-cell contact in the developing dLGN during laminar segregation to look for ultrastructural correlates of the intercellular affinity or adhesion we have hypothesized. The present results have been presented previously in abstract from (Brunso-Bechtold and Vinsant, 1986). 


\section{Materials and Methods}

In the present study, we examined the dLGN from tree shrews sacrificed before (postnatal day $0^{\prime} ; \mathrm{P0}$ ), during (P4 and P8), and after (P15 and P90) laminar segregation. The same cases were used as in the preceding study (Brunso-Bechtold and Vinsant, 1988), and the reader is referred to that paper for the details of tissue preparation. Briefly, 2 animals from each time point were overdosed with sodium pentabarbital, transcardially perfused with a fixative of $2 \%$ paraformaldehyde, $2 \%$ glutaraldchydc in $0.15 \mathrm{~m}$ sodium cacodylate buffer, and stored in the samc fixative overnight at $4^{\circ} \mathrm{C}$. The next day the brains were removed from the skull and sectioned horizontally on a vibratome; the binocular segment of the dLGNs from the middle third of the nucleus (dorsoventrally) was cut out, and the blocks were dehydrated, osmicated, and embedded in Araldite. Thin sections were cut on an LKB 4800 ultramicrotome, collected onto Formvar-coated slot grids, stained, and viewed on an Hitachi $600 \mathrm{CX}$ electron microscope. Although the location of each micrograph was not documented as it was in the preceding study, each block contained only dLGN, insuring that all observations are from that nucleus. Furthermore, as each thin section included the mediolateral extent of the nucleus, and as the entire section was studied, the observations reported here are not restricted to any specific layers or interlaminar regions.

\section{Results}

Before and during the segregation of dLGN layers, cells are often present in groups with juxtaposed plasma membranes. A lowpower electron micrograph illustrating a group of dLGN cells at P4 is shown in Figure 1. A higher-power micrograph of 2 adjacent cells in a similar group is shown in Figure 2, illustrating the extent of the plasma membranes in immediate contact. At each age, these areas of contact were examined for the presence of membrane specializations.

In order to be certain that all membrane specializations included in the present study reflect the interrelationship between 2 different neuronal somata, all analyses were done on juxtaposed neurons, both of which contained a distinct nucleus and nucleolus, thereby demonstrating that the membranes belonged to 2 different cells rather than to separate parts of a single cell. Thus, all examples presented here are from the immediately adjacent portions of 2 neurons; however, because of the increased magnification of some of the photomicrographs, the nuclei of these adjacent neurons cannot be seen.

At none of the ages studied are gap junctions evident either between adjacent neurons or between neurons and processes in the surrounding neuropil. However, puncta adherentes are present between adjacent neurons. Although these are most frequent at ages when large groups of cells are commonly seen (i.e., before and during laminar segregation: Figs. $3 A, \mathrm{P} 0 ; 3 B, \mathrm{P} 4)$, these junctions also can be seen in older animals in the rare instances in which neurons are immediately adjacent. Figure $3 C$ illustrates such an example between 2 neurons in a mature tree shrew (P90). Furthermore, puncta adherentes are not only present between adjacent neurons, they are also present between cells and processes in the surrounding neuropil.

We also frequently observe the presence of subsurface cisternae, which are segments of endoplasmic reticulum layered just under the surface of the plasma membrane. These can be seen at all ages, although they may be somewhat more common before and during laminar segregation. Figure $4 A$ illustrates a subsurface cistern extending from the outer nuclear membrane of a neuron at P7; in this example the subsurface cistern is adjacent to a cytoplasmic process in the neuropil. These profiles are present singly and in pairs. A pair of subsurface cisternae

\footnotetext{
' We consider the first day of life to be postnatal day 0 or PO, the second day of life to be P1, and so on.
}

on either side of the plasma membranes of 2 adjacent neuronal somata, also at P7, is illustrated in Figure $4 B$. An example of 2 subsurface cisternae within the same cell from the dLGN of a $\mathrm{P0}$ tree shrew is illustrated in Figure $4 C$.

In addition to the membrane specializations described above, close inspection of segments of juxtaposed neuronal plasma membranes reveals the very occasional presence of cytoplasmic bridges. An example of a cytoplasmic bridge at $\mathrm{P} 0$ is illustrated in Figure $5 A$; note the membranous sac at the confluence of the 2 cells (arrow). In order to be certain that these profiles are not artifactual, a very rigid set of criteria had to be met before such a profile was considered to be a cytoplasmic bridge. First, and most obvious, the membrane preservation of the other elements in that case had to be excellent. Second, there had to be some structural continuity between the adjacent cells, such as microfilaments or vesicles, that bridged the confluence between the cells. Third, each example was rotated using a goniometer along an axis parallel with that of the juxtaposed membranes to be certain that plasma membranes were not present across the apparent confluence but simply out of focus due to the plane of section. Only if all 3 of these criteria were met was a profile considered to be a cytoplasmic bridge. Another example of a cytoplasmic bridge with several vesicles (left arrow) at the confluence of the 2 cells is shown in Figure $5 B$; the right arrow indicates a punctum adherens. However, these profiles are only infrequently present before and during laminar segregation and are never seen after the cell layers have formed.

In our analyses of juxtaposed segments of adjacent neuronal somata, it became clcar that there were often thin cytoplasmic processes interdigitated between otherwise immediately abutting plasma membranes. An example of cytoplasmic processes between adjacent cells is illustrated at P14 (Fig. 6A) and P7 (Fig. $6 B$ ). Not only are these processes present between adjacent neuronal somata, they are often present (sometimes in "stacks") on other surfaces of the neuronal somata (Fig. $6 C$, P4). Whether these processes are filopodia of neuronal growth cones or glial processes cannot be unequivocally determined in this material. They are, however, strikingly similar in appearance to the glial processes in the adult dLGN. Figure 7 illustrates an example of glial processes (arrows, Fig. $7 A$ ) adjacent to an adult neuron, as well as glial encapsulation (arrows, Fig. $7 B$ ) of retinogeniculate terminals in the adult tree shrew.

Because of the possibility that the cytoplasmic processes we observed were glial in origin, we made a preliminary ultrastructural survey of whether glia can be distinguished in the tree shrew dLGN at this stage of development. For comparison with glial morphology during this period, Figure 8 illustrates examples of neuronal morphology at P4 (Fig. 8A), P7 (Fig. 8B), and P15 (Fig. 8C). Nuclear chromatin is somewhat clumped, with no evidence of a ring of heterochromatin lining the nuclear membrane. The cytoplasm is relatively light and clear, and there are relatively few free polyribosomes. Rough endoplasmic reticulum, Golgi apparatus, and mitochondria are evident.

By $\mathrm{PO}$ in tree shrews, some non-neuronal profiles are clearly present. There are a few immature oligodendrocytes present near the optic tract, but myelin figures are not seen. Astrocytes can be distinguished immunocytochemically in the ferret dLGN at a comparable stage of development (Brunso-Bechtold, unpublished observations). Nevertheless, on the basis of ultrastructural criteria, most P0 glia appear to be glioblasts, which are distinct from neurons but are difficult to categorize as astrocytes, oligodendrocytes, or microglia. By $\mathrm{P} 4$, astrocytes can more readily 


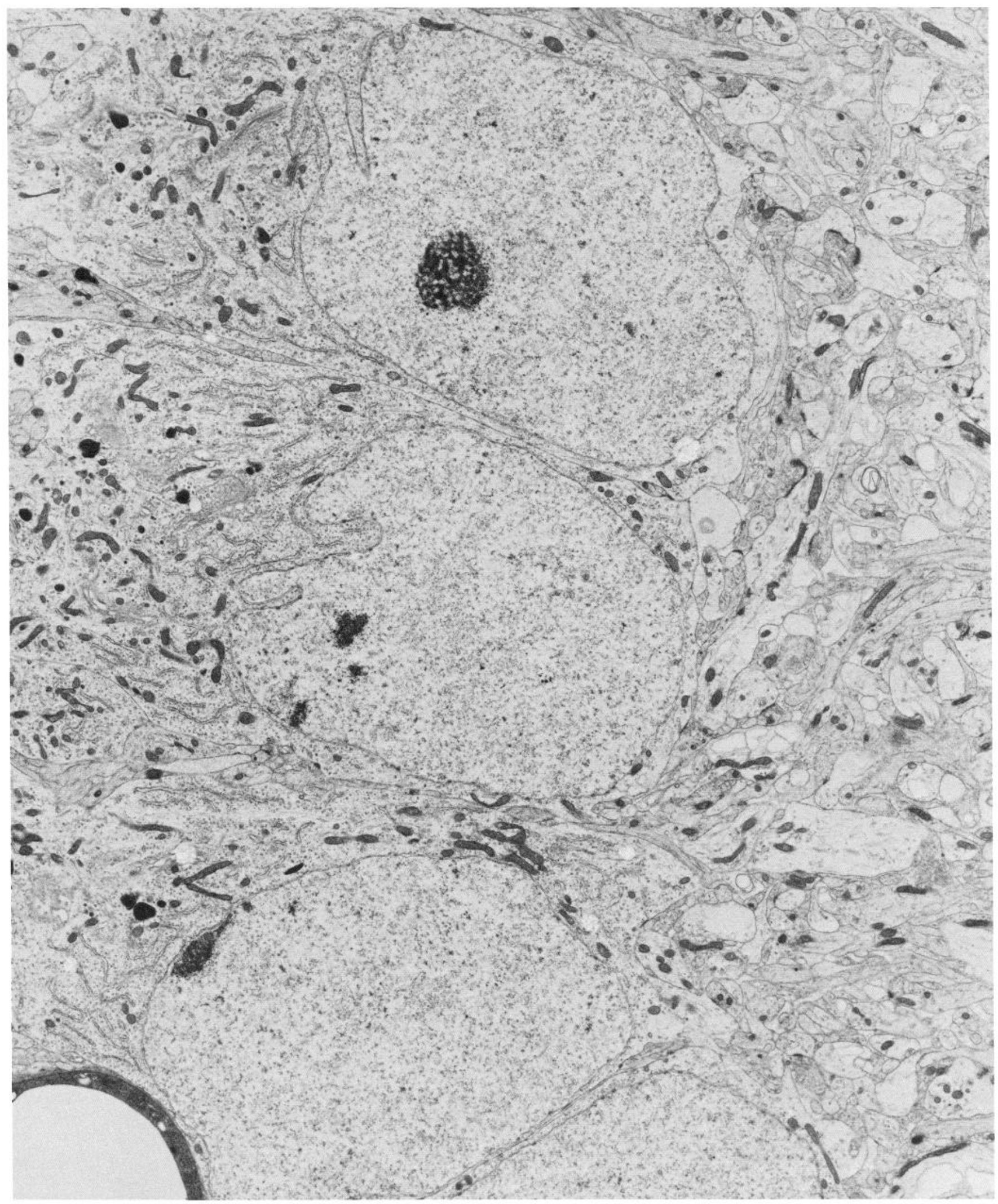

Figure 1. Group of adjacent cells at P4 in the tree shrew dLGN. Before and during the segregation of dLGN cell layers, cells can be seen in groups with immediately adjacent plasma membranes. $\times 7500$. 


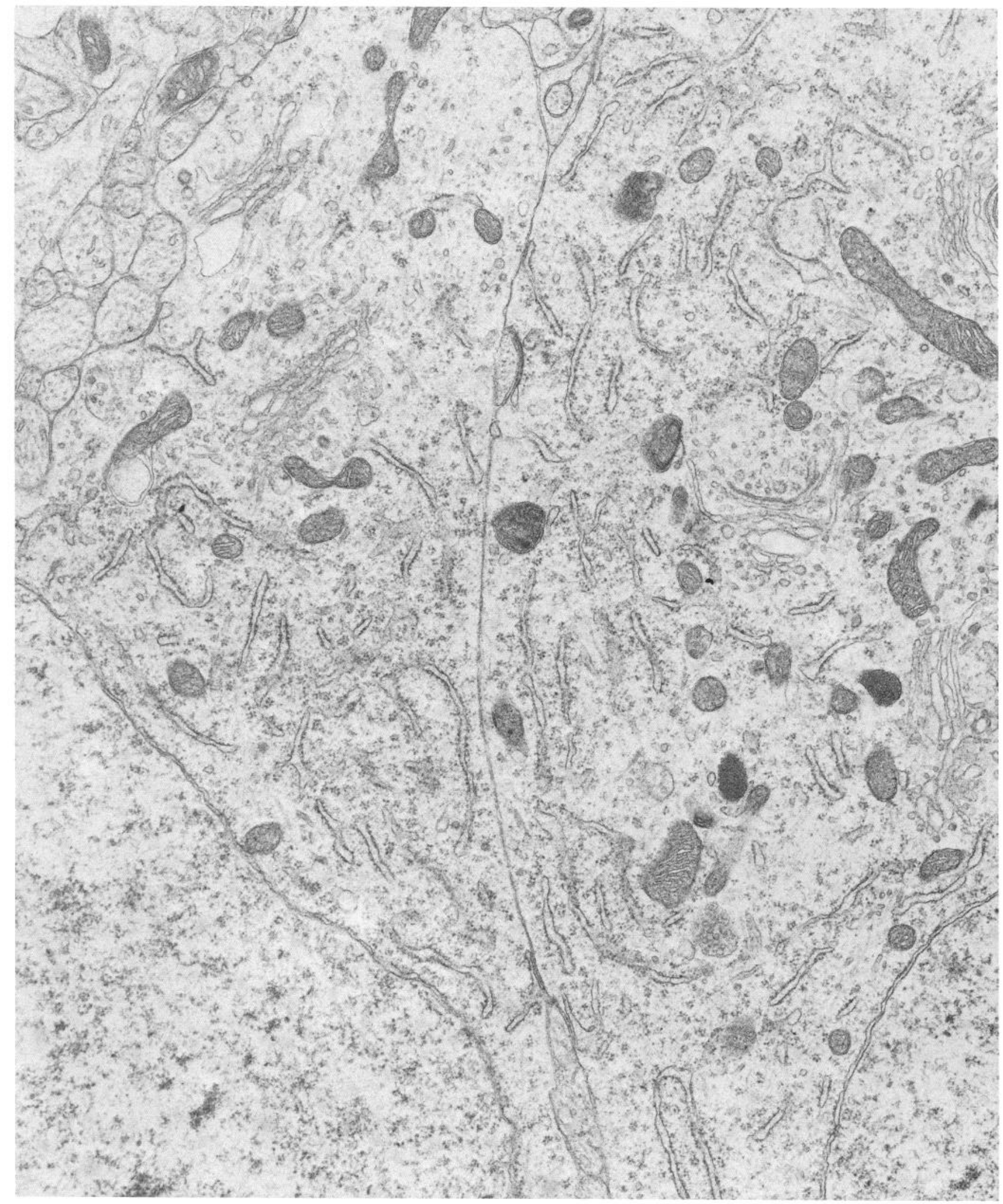

Figure 2. Segment of juxtaposed plasma membranes between two adjacent neurons. This example is from the tree shrew dLGN at P4 but is typical of adjacent neurons before and during cell segregation. $\times 24,000$. 

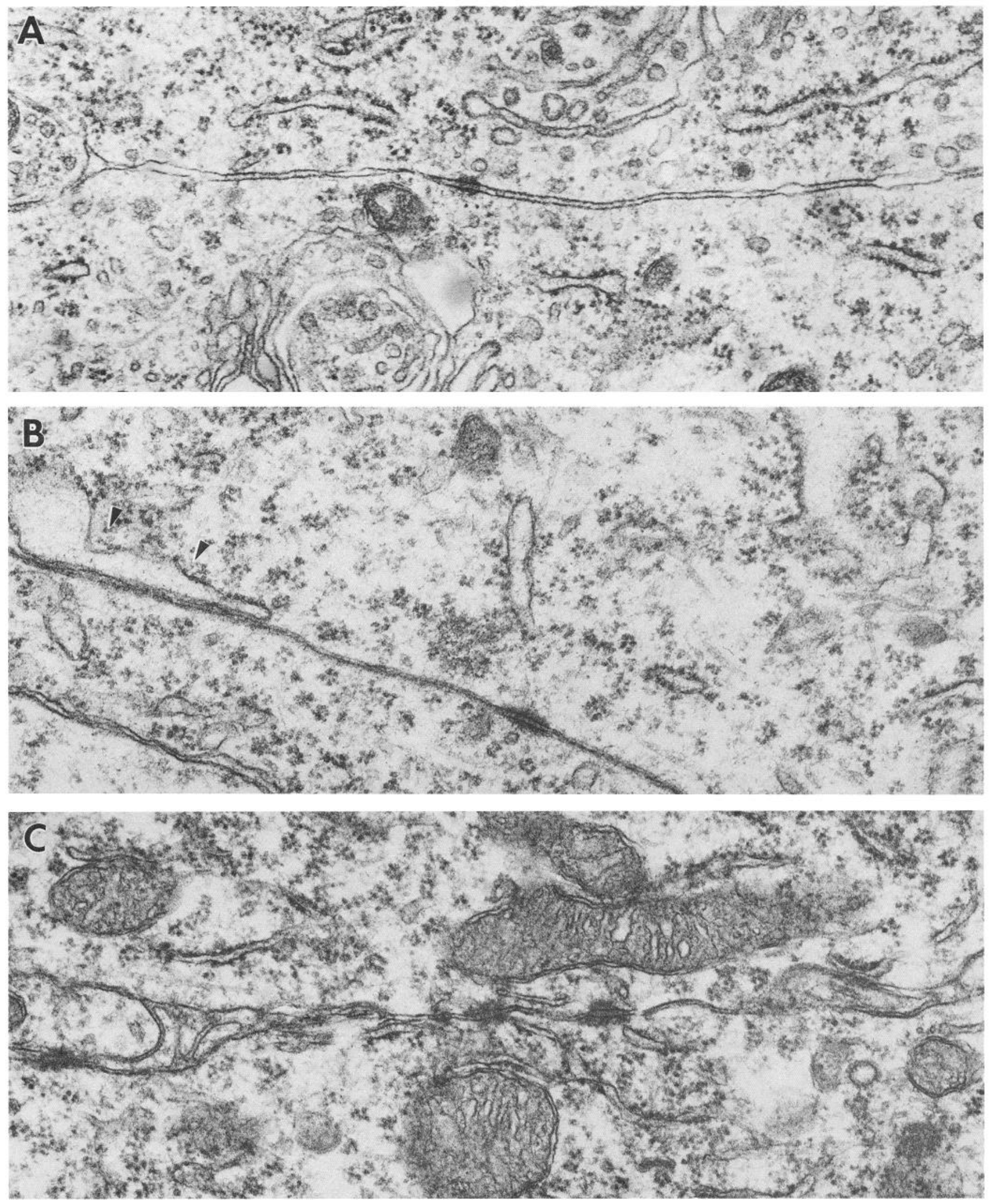

Figure 3. Puncta adherentes in the developing tree shrew dLGN. Puncta adherentes are occasionally seen whenever neurons are adjacent to each other. Examples are illustrated at P0 $(A), \mathrm{P} 4(B)$, and P90 $(C) . \times 54,000$. 

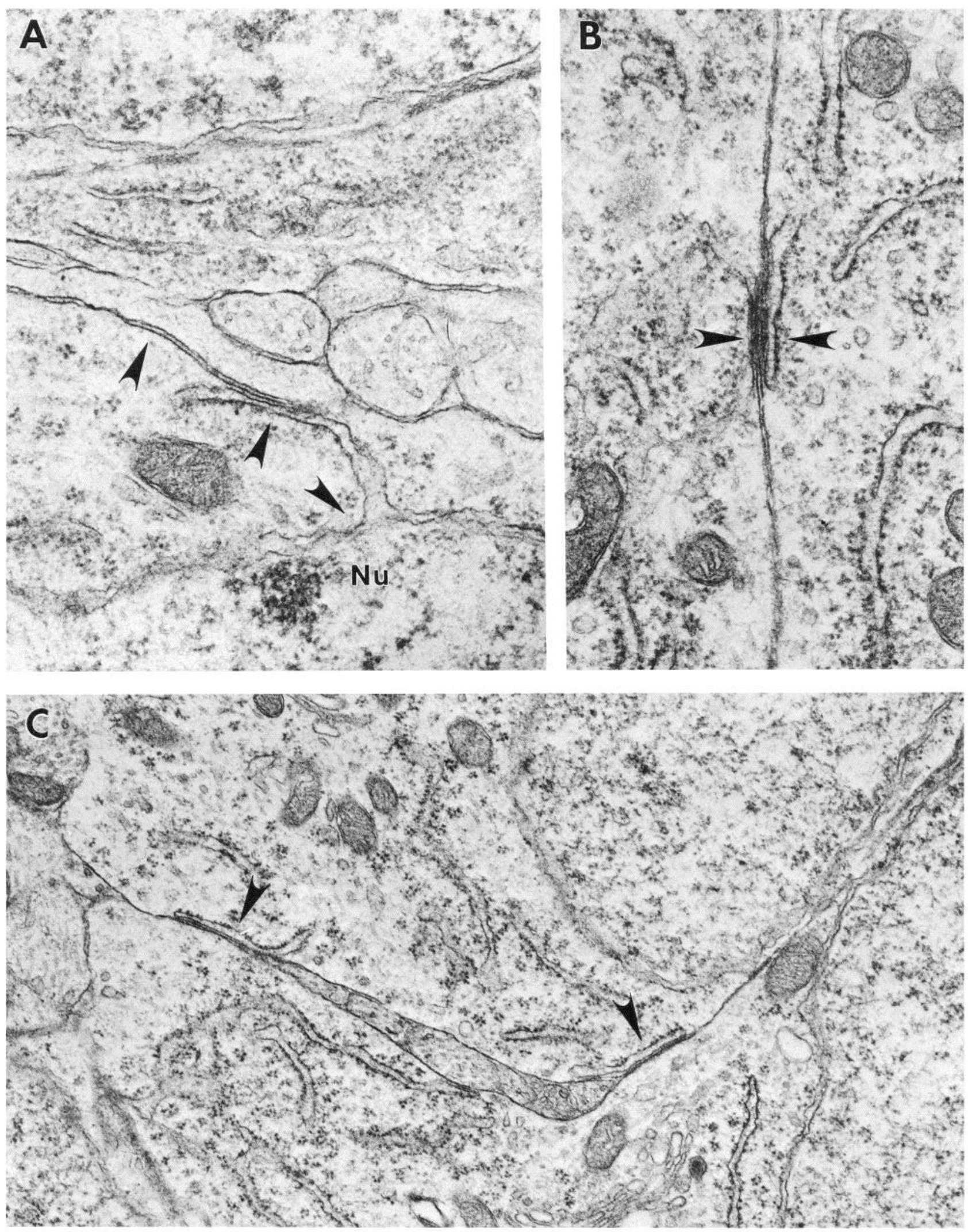

Figure 4. Subsurface cisternae in the developing tree shrew dLGN. Subsurface cisternae are seen at all stages of dLGN development although they may be somewhat more prevalent before and during cell layer formation. A, Lower 2 arrowheads indicate a subsurface cisterna that is an extension of the outer nuclear membrane and is found adjacent to a cytoplasmic process at P7; upper arrowhead indicates juxtaposition of the plasma membranes of the neuron and the cytoplasmic process. $\times 33,750 . B$, A pair of subsurface cisternae (arrowheads) along the plasma membrane of 2 different, immediately adjacent neuronal somata at P7. $\times 50,000$. C, Two subsurface cisternae (arrowheads) just under the plasma membrane of a neuron in contact with an adjacent neuronal somata at $\mathrm{P} 0 . \times 50,000 . \mathrm{Nu}$, nucleus. 

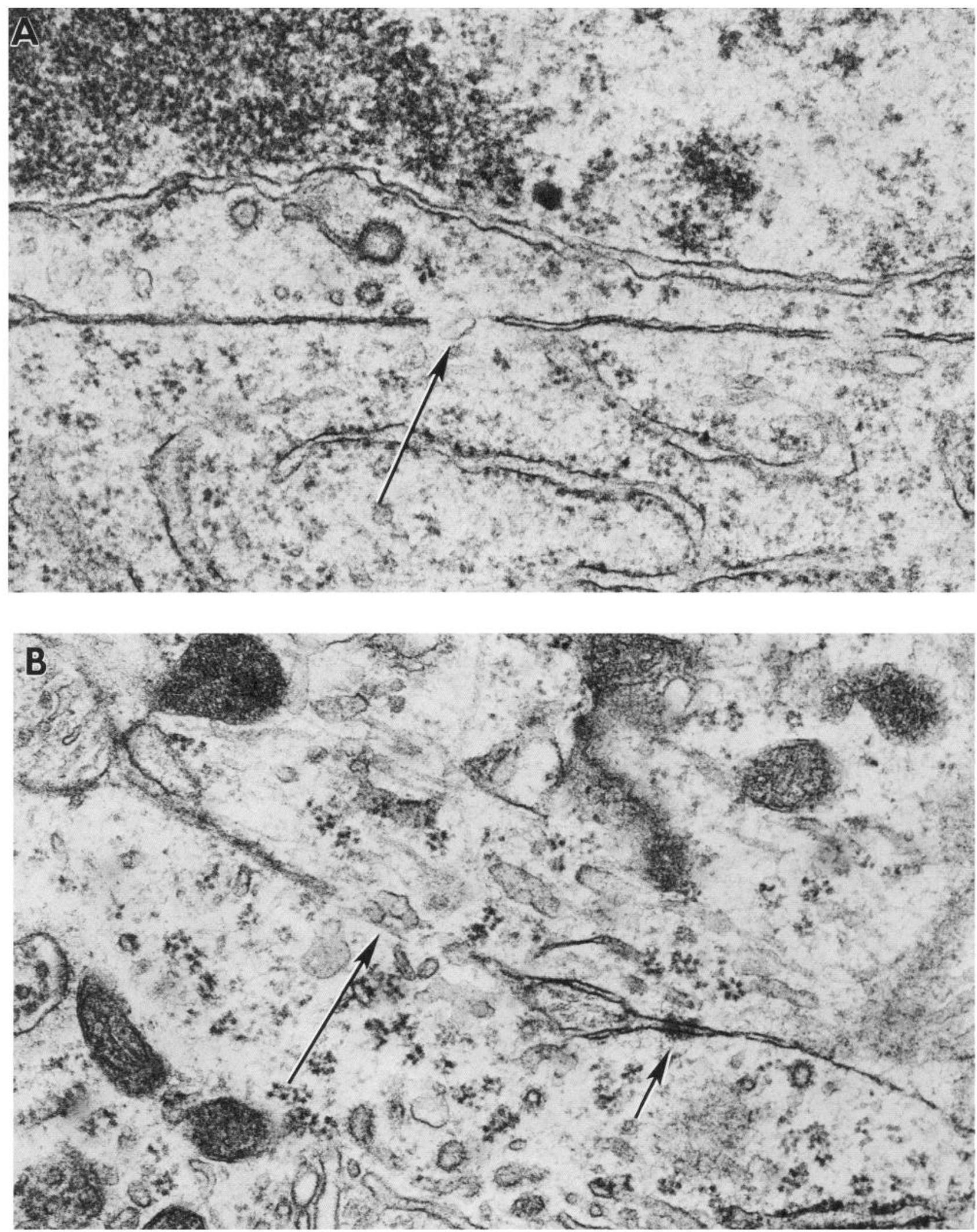

Figure 5. Cytoplasmic bridges in the developing tree shrew dLGN. Although rare, cytoplasmic bridges such as these in the tree shrew at P0 $(A)$ and P7 $(B)$ are seen before and during but not after cell layer segregation. Such bridges have been reported in other systems and have been hypothesized to synchronize the differentiation of developing cells (see text). Long arrows point to membranous vesicles at the site of the cytoplasmic bridges. Short arrow points to a punctum adherens. $\times 67,000$. 

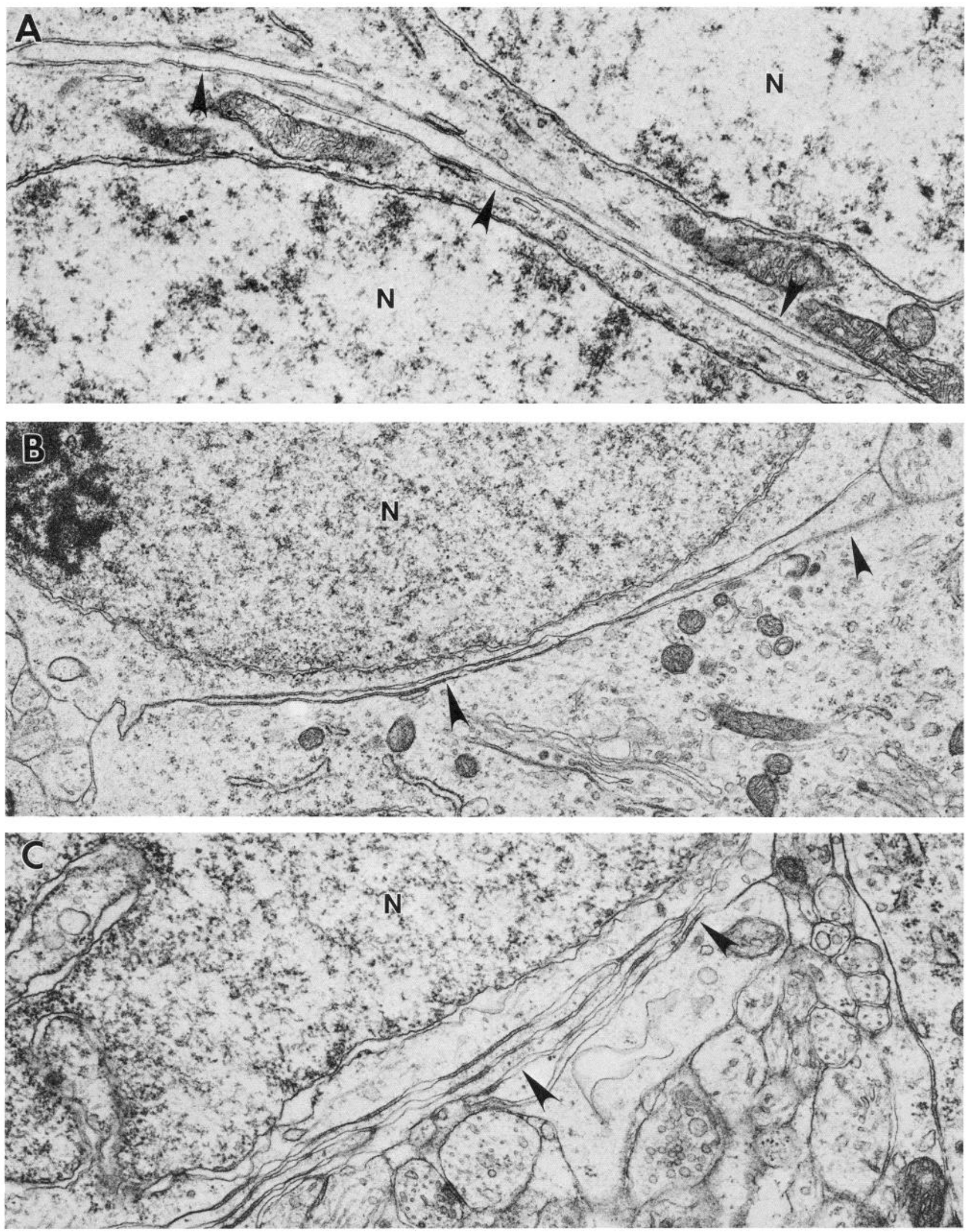

Figure 6. Cytoplasmic processes in the developing tree shrew dLGN. Cytoplasmic processes (arrowheads) are common features of all the immature ages we have studied. In $A(\mathrm{P} 14)$ and $B(\mathrm{P} 7)$ they are interposed between otherwise immediately adjacent neuronal somata. Subsurface cisternae in $A$ are present in each neuron adjacent to the cytoplasmic process. The processes are also found along the outside surface of the somata as illustrated in $C$ (P4). $N u$, nucleus. $A, \times 33,600 ; B, \times 21,600 ; C, \times 28,000$. 

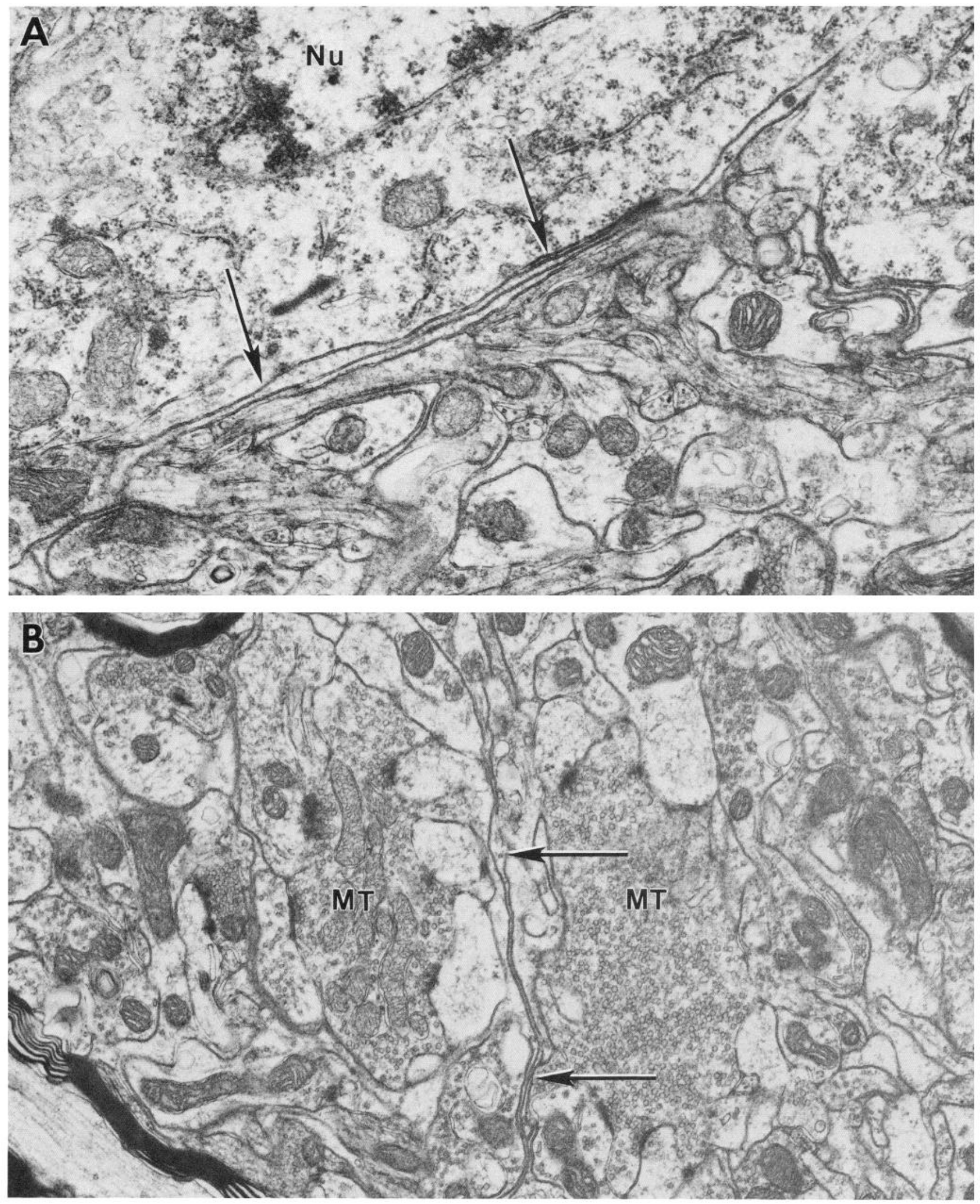

Figure 7. Glial processes in the adult dLGN. Arrows in $A$ (P90) indicate glial processes adjacent to neuronal somata in the adult. Arrows in $B$ indicate glial process encapsulating the multiple terminal (MT) in the adult. Note the similarity in appearance to the cytoplasmic processes observed during development. $N u$, nucleus. $A, \times 21,600 ; B, \times 32,400$. 

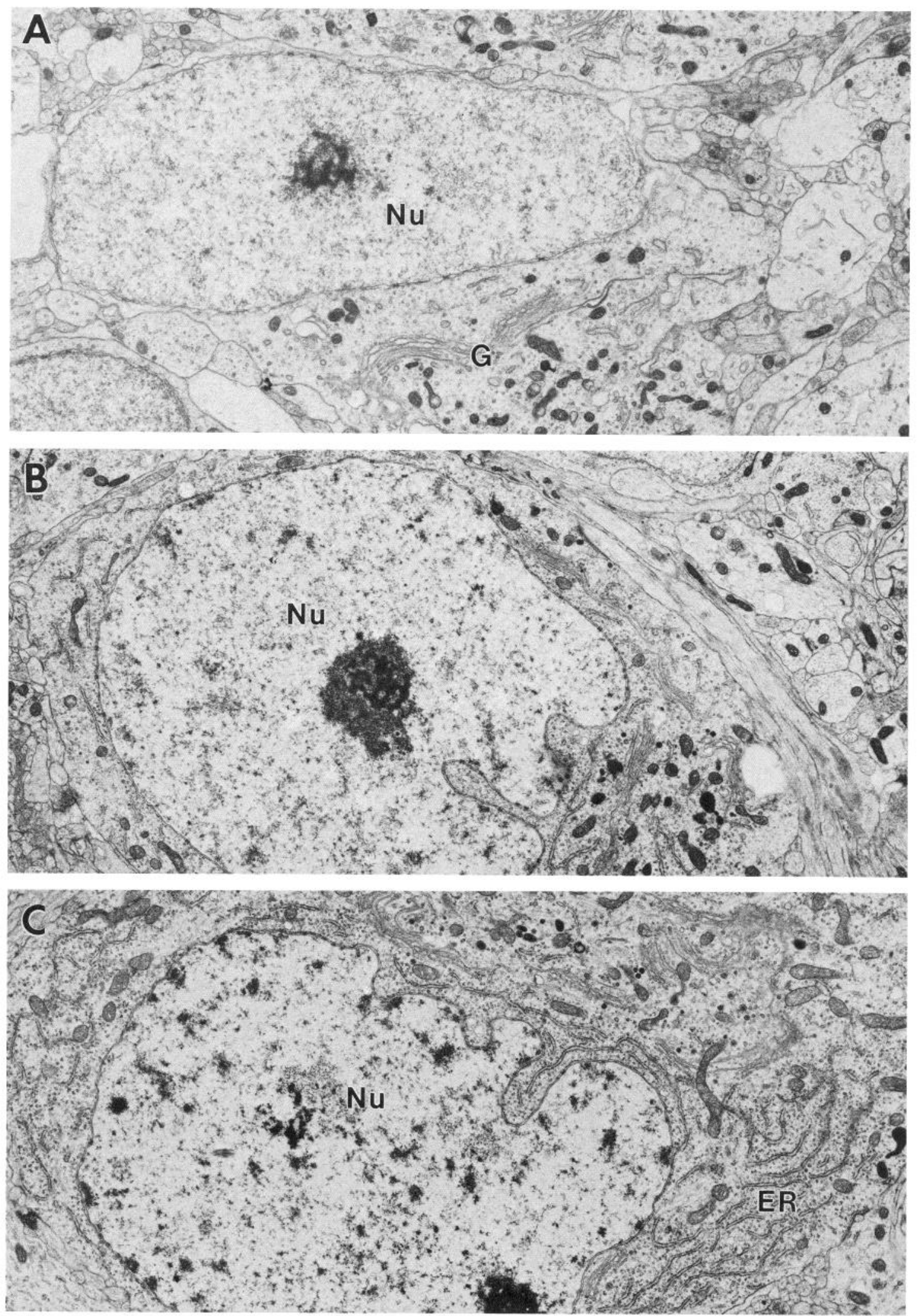

Figure 8. Immature neurons in the developing tree shrew dLGN. Examples of neurons are shown from P4 $(A, \times 10,000)$, P7 $(B, \times 8000)$, and P15 $(C, \times 8750)$. Neurons, in contrast to immature glia, have relatively few free ribosomes; narrow-bore rough endoplasmic reticulum, not arranged in a definitive pattern; somewhat clumped nuclear chromatin with no evidence of deposits of heterochromatin at the periphery of the nucleus. Large nucleoli are common. $N u$, nucleus; $G$, Golgi apparatus; $E R$, endoplasmic reticulum. 

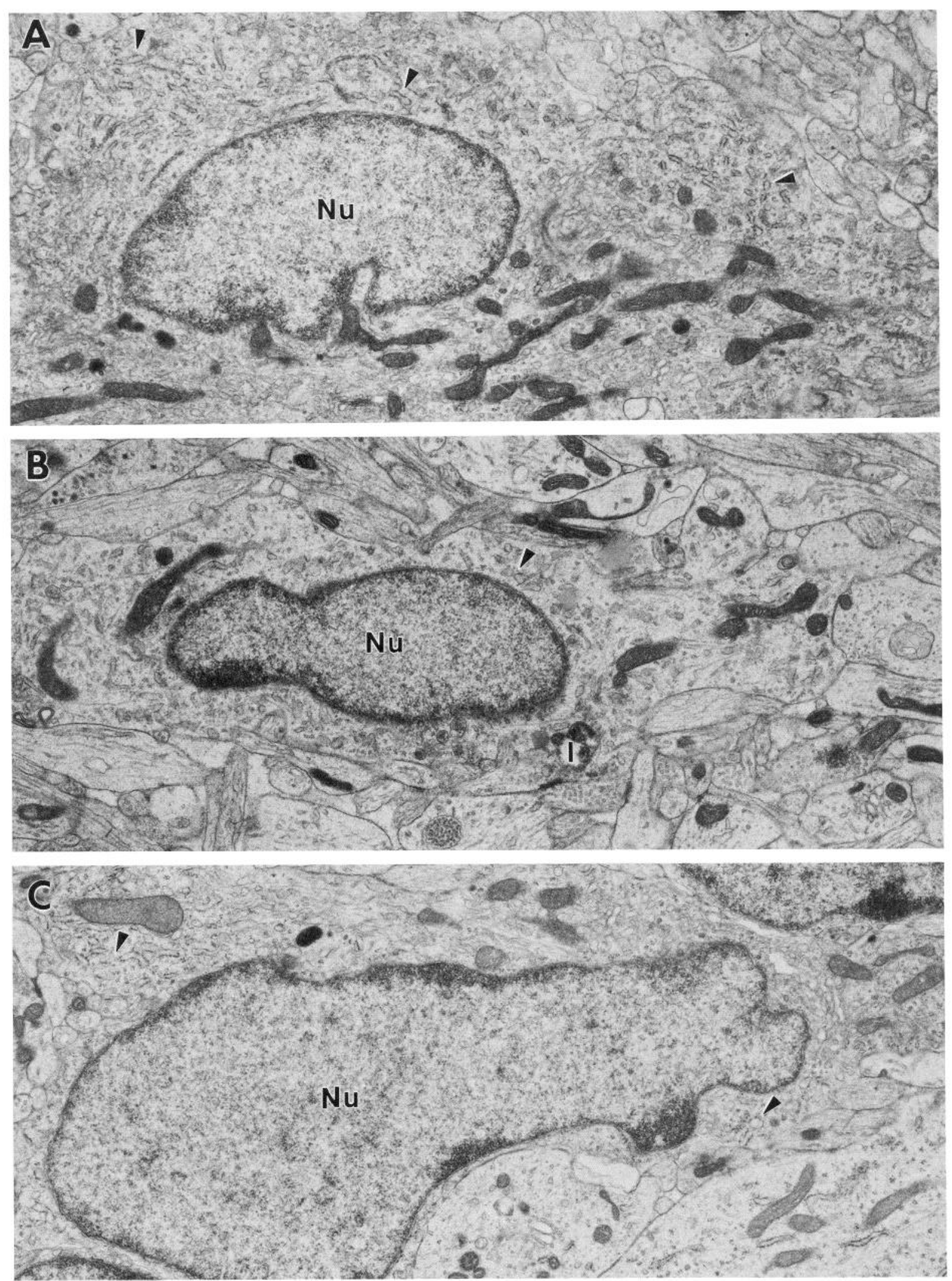

Figure 9. Immature astrocytes in the developing tree shrew dLGN. Immature astrocytes can be distinguished on the basis of ultrastructural criteria at P4: (1) ring of heterochromatin at the periphery of the nucleus, (2) otherwise homogeneous nuclear euchromatin, (3) paler cytoplasm than in oligodendrocytes, and (4) usually enlarged, densely filled cisternae of rough endoplasmic reticulum (arrowheads). Immature astrocytes are illustrated at $A(\mathrm{P} 4), \times 11,000 ; B(\mathrm{P} 7), \times 13,500$; and $C(\mathrm{P} 15), \times 13,500 . N u$, nucleus; $I$, astrocytic inclusion body. 

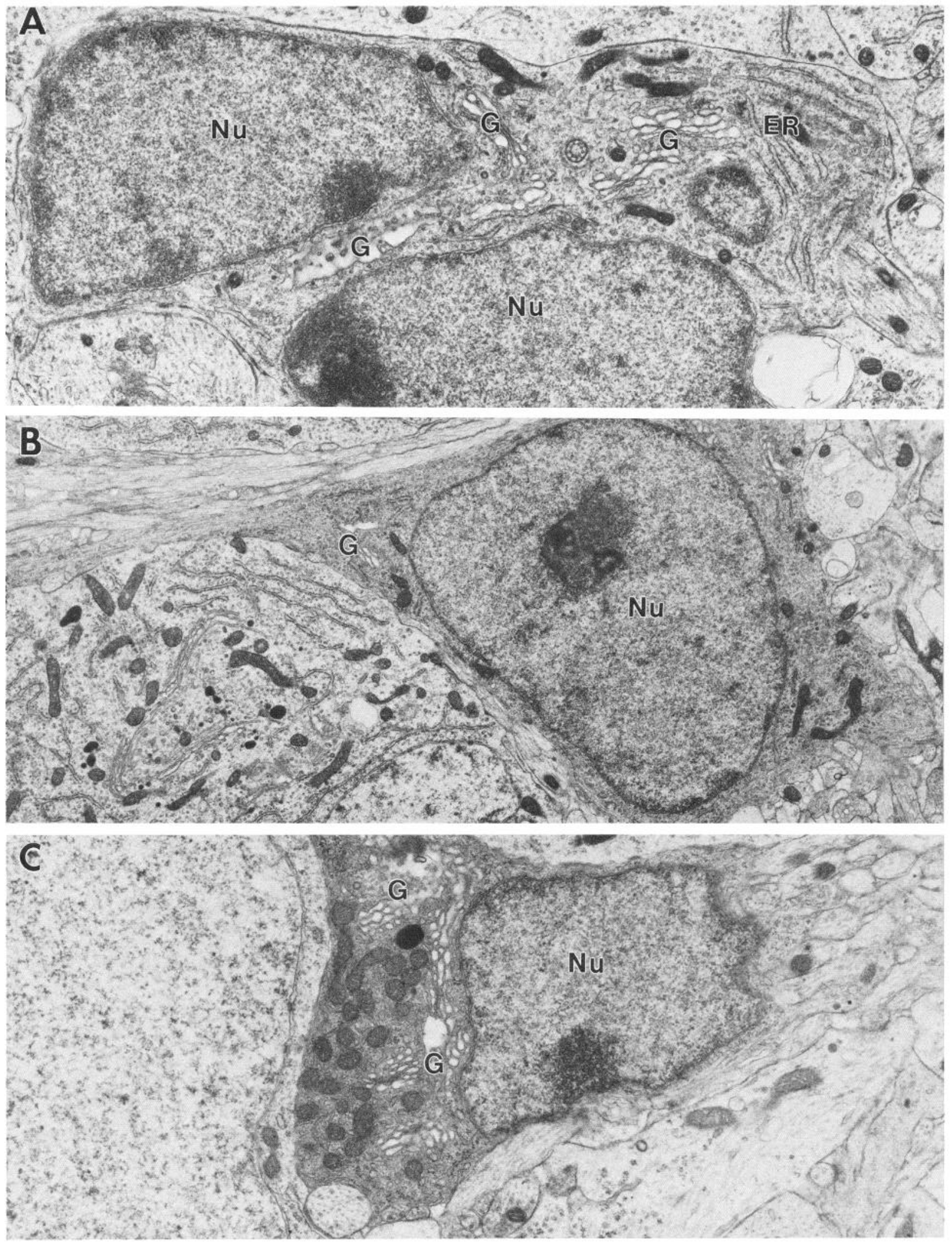

Figure 10. Immature oligodendrocytes in the developing tree shrew dLGN. A few oligodendrocytes can be distinguished at P0, mostly near the optic tract, although myelinated fibers are not seen. We could distinguish immature oligodendrocytes on the basis of the following criteria: (1) dense, often blotchy chromatin in the nucleus; (2) usually many neurotubules and free ribosomes; (3) endoplasmic reticulum studded irregularly with ribosomes and often present in regular rows; (4) frequently abundant and enlarged Golgi apparatus; and (5) cytoplasm denser than in astrocytes. Immature oligodendrocytes are illustrated at $A(\mathrm{P} 4), \times 15,600 ; B(\mathrm{P} 7), \times 9625$; and $C(\mathrm{P} 15), \times 17,000$. $N u$, nucleus; $G$, Golgi apparatus; $E R$, endoplasmic reticulum. 
be distinguished on the basis of a ring of heterochromatin at the periphery of the nucleus, with otherwise generally homogeneous euchromatin throughout the nucleus, distended cisternae of rough endoplasmic reticulum filled with relatively dense material (arrowheads, Fig. 9A), and paler cytoplasm than is found in oligodendrocytes (Vaughn and Peters, 1974; Skoff et al., 1976; Parnavelas et al., 1983). Astrocytes of similar appearance are also present at P7 (Fig. 9B) and P15 (Fig. 9C).

Although unlikely to be the source of the cytoplasmic processes we see, oligodendrocytes in the dLGN can also be distinguished at P4. The nucleus contains dense, often blotchy chromatin. The cytoplasm is considerably denser than that of astrocytes, and there are many free ribosomes, as well as narrowbore cisternae of rough endoplasmic reticulum irregularly studded with ribosomes, many neurotubules, and abundant Golgi profiles (Fig. 10A) (Vaughn and Peters, 1974; Skoff et al., 1976; Parnavelas et al., 1983). Examples of oligodendrocytes at P7 and P15 are illustrated in Figure $10, B$ and $C$, respectively.

\section{Discussion}

The goal of the present investigation was to determine whether ultrastructural profiles exist that might mediate the cell-cell affinity or adhesion we have hypothesized during the period of cell layer segregation in the dLGN. To achieve this goal, we examined juxtaposed segments of neuronal plasma membranes in the groups of dLGN cells that we have reported to be present before and during the segregation of dLGN cell layers (BrunsoBechtold and Casagrande, 1985). While our results have not revealed any definitive ultrastructural correlates of an intercellular affinity between dLGN cells, we have observed specialized profiles that help to characterize the intercellular relationships before, during, and after laminar segregation.

\section{Membrane specialization}

Puncta adherentes have long been recognized to play a role in the physical attachment of adjacent cells to each other (McNutt and Weinstein, 1973; Ginzberg et al., 1985). And perhaps not surprisingly, these profiles are occasionally present when cells are adjacent to each other regardless of developmental stage. Careful analysis of cell groupings before and during laminar segregation, however, reveals that these profiles are by no means sufficiently prevalent to be a major mechanism of specific cellular adhesion during that time.

Gap junctions are known to be involved in cellular coupling and are found in several different regions of the developing embryo (Potter et al., 1966; Ginzberg et al., 1985; see Caveney, 1985 , for review), as well as specifically in the developing nervous system (Hayes and Roberts, 1975; Møllgord and Møller, 1975). We therefore anticipated that these profiles might also be present between immediately adjacent cells during the period of laminar segregation. Despite careful survey of the tissue however, we have been unable to find any evidence of gap junctions between dLGN neuronal somata during the period of cell layer segregation.

Another membrane specialization, the subsurface cisterna, has been reported widely in the nervous system, although it has not been described in detail during development. This specialization has been reported to be present only in neurons but to be positioned adjacent to glia (Siegesmund, 1968), as well as other neurons (Fisher and Goldman, 1975; Hervás and Lafarga, 1979). The major function is believed to be more closely related to intercellular communication than adhesion (Rosebluth, 1962).
Consequently, the subsurface cisternae in the developing dLGN may be playing a role not unlike that hypothesized for gap junctions in other tissues. Especially in instances in which the subsurface cisternae appear in pairs, the positioning of the layers of endoplasmic reticulum just under the plasma membrane, and thus the potential for affecting the neuronal surface, seems particularly well suited to neuron-neuron or neuron-glia communication (see also Ie Beux, 1972; Watanabe and Burnstock, 1976).

\section{Cytoplasmic bridges}

Although cytoplasmic bridges are only rarely found in our material, they merit mention for several reasons. First, they are found in tissue in which other membranes are excellently preserved without discontinuities. Second, they are present only before or during the time cell layers are segregating; they are never seen after P7. Furthermore, such structures have been documented in other developing systems. Das $(1975,1977)$ reported that they are present in the developing cerebellum and, with serial reconstruction, showed that the vesicles which are often present in the confluence between the 2 cells result in a lattice of narrow continuities between adjacent cells. If hypothesized that the cytoplasmic bridges could play a role in synchronizing cell differentiation. "Incomplete cytokinesis," which closely resembles the cytoplasmic bridges described here, has also been reported in the immature bat raphe nuclei (Machin et al., 1983). In the dLGN it is unlikely that the cytoplasmic continuities we occasionally see are due to incomplete cell division since cells divide in the subventricular zone and then migrate to the lateral surface of the diencephalon (Rakic, 1977). Cytoplasmic bridges have also been observed in the developing chick trigeminal system (Heaton and Moody, 1980), as well as in a very different system, the tubular accessory gland of the meal worm (Happ and Happ, 1982). In the latter system, they are also believed to play a role in synchronizing differentiation.

One interesting possibility then is that these cytoplasmic bridges could play a role, perhaps in conjunction with subsurface cisterns, in synchronizing the differentiation of dLGN cclls. Accordingly, once all cell layers have begun to segregate, the cells would differentiate in synchrony. If the plasma membranes of adjacent dLGN cells adhere to one another by molecular cell surface affinities, the composition of the cell surface might then be altered to result in reduced interneuronal affinities. Such a possibility is certainly consistent with our observation that, after the segregation of dLGN cell layers, the neuronal somata are no longer found in large groups with much of their plasma membranes in immediate contact.

\section{Cytoplasmic processes}

The frequent interdigitation of fine cytoplasmic processes between otherwise immediately adjacent neuronal plasma membranes before and during dLGN laminar segregation raises the issues both of the identity of these processes and of what role they might play in that segregation. With respect to their identity, it is impossible at this point to be certain whether they are filopodia of neuronal growth cones or fine extensions of developing astrocytes. Only serial reconstruction and/or electron microscopic immunocytochemistry will allow absolute determination. Some of the profiles share many of the features of growth cones (Brunso-Bechtold and Vinsant, 1988), having a meshwork of microfilaments, few organelles, and occasional membranous sacs or vesicles. Reports in the literature suggest that the absence 
of ribosomes and intermediate filaments distinguish processes as neuronal growth cones rather than extensions of glia (Williams et al., 1986). However, the fine glial processes that encapsulate the retinogeniculate terminals generally do not appear to contain those organelles. In summary, we feel it is premature to identify these profiles as either neuronal or glial in origin; in fact, they may well be comprised of both.

Regardless of the origin of the cytoplasmic processes, the question arises of what their role might be in the developing dLGN. If they are neuronal growth cones, they may be using the surface of the dLGN neurons for pathfinding. Conversely, if they are glial processes, they may be playing a role in intercellular communication via subsurface cisterns or in the intercellular affinity we have hypothesized between cells destined to occupy the same layer. They could, for example, be essentially "holding together" cells within a layer via a combination of mechanical and molecular cell surface mechanisms. Considerable recent evidence points to such involvement of glia in the developing cytoarchitecture of structures in the CNS (e.g., Cooper and Steindler, 1986; Hatten and Mason, 1986), as well as in developing fiber pathways (Silver, 1984). Clearly, the final resolution of this issue awaits further investigation.

\section{References}

Brunso-Bechtold, J. K., and V. A. Casagrande (1982) Early postnatal development of laminar characteristics in the dorsal lateral geniculate nucleus of the tree shrew. J. Neurosci. 2: 589-597.

Brunso-Bechtold, J. K., and V. A. Casagrande (1985) Ultrastructure of the developing tree shrew lateral geniculate nucleus. Dev. Brain Res. 23: 310-314.

Brunso-Bechtold, J. K., and S. L. Vinsant (1986) Cell-cell relationships in the developing lateral geniculate nucleus. Soc. Ncurosci. Abstr. 12: 590.

Brunso-Bechtold, J. K., and S. L. Vinsant (1988) Distribution of growth cones and synapses in developing laminar and interlaminar regions of the dorsal lateral geniculate nucleus. J. Neurosci. 8: 2677-2692.

Caveney, S. (1985) The role of gap junctions in development. Annu. Rev. Physiol. 47: 319-335.

Cooper, N. G. F., and D. A. Steindler (1986) Lectins demarcate the barrel subfield in the somatosensory cortex of the early postnatal mouse. J. Comp. Neurol. 249: 157-169.

Cusick, C. G., and J. H. Kaas (1982) Retinal projections in the adult and newborn grey squirrels. Dev. Brain Res. 4: 275-284.

Das, G. D. (1975) Transient cytoplasmic bridges among the cells of developing cerebellum: A possible mode of induction for cell differentiation. Cell Diff. 3: 371-377.

Das, G. D. (1977) Membrane-fusions and cytoplasmic bridges in the cells of the developing cerebellum. Cell Tissue Res. 176: 475-492.

Fisher, S. K., and K. Goldman (1975) Subsurface cisterns in the vertebrate retina. Cell Tissue Res. 164: 473-480.

Ginzberg, R. D., E. A. Morales, D. C. Spray, and M. V. L. Bennet (1985) Cell junctions in early embryos of squid. Cell Tissue Res. 239: 477-484.

Guillery, R. W.. A. S. LaMantia, J. A. Robson, and K. Huang (1985) The influence of retinal afferents upon the development of layers in the dorsal lateral geniculate nucleus of Mustelids. J. Neurosci. 5:13701379.
Happ, G. M, and C. M. Happ (1982) Cytodifferentiation in the accessory glands of the tenebrio-molitor 10 . Ultrastructure of the tubular gland in the male pupa. J. Morphol. 172: 97-112.

Hatten, M. E., and C. Mason (1986) Neuron-astroglia interactions in vitro and in vivo. Trends Neurosci. 9: 168-174.

Hayes, B. P., and A. Roberts (1975) The distribution of non-synaptic intercellular junctions during neurone differentiation in the developing spinal cord of the clawed toad. J. Embryol. Exp. Morphol. 33: 403-417.

Heaton, M. B., and S. A. Moody (1980) Early development and migration of the trigeminal motor nucleus in the chick embryo. J. Comp. Neurol. 189: 61-99.

Hervás, J.-P., and M. Lafarga (1979) Subsurface cislerns in paraventricular nuclei of the hypothalamus of the rat. Cell Tissue Res. 199: 271-279.

Le Beux, Y. J. (1972) Subsurface cisterns and lamellar bodies: Particular forms of the endoplasmic reticulum in the neurons. Z. Zellforsch. 133: 327-352.

Linden, D. C., R. W. Guillery, and J. Cucchiaro (1981) The dorsal lateral geniculate nucleus of the normal ferret and its postnatal development. J. Comp. Neurol. 203: 189-211

Machin, C., C. Rua, E. Taber-Pierce, and A. Carrato (1983) Ultrastructural development of Raphe nuclei in the bat (Myotis myrtis). $\mathbf{J}$. Hirnforsh. 24: 405-414.

McNutt, N. S., and R. S. Weinstein (1973) Membrane ultrastructure at mammalian intercellular junctions. Prog. Biophys. Mol. Biol. 26 . $47-101$.

Møllgard, K., and M. Møller (1975) Dendrodendritic gap junctions: A developmental approach. Adv. Neurol. 12: 79-89.

Parnavelas, J. G., R. Luder, S. G. Pollard, K. Sullivan, and A. R. Lieberman (1983) A qualitative and quantitative ultrastructural study of glial cells in the developing visual cortex of the rat. Phil. Trans. R. Soc. London [Biol.] 301: 55-84.

Potter, D. D., E. J. Furshpan, and E. S. Lennox (1966) Connections between cells of the developing squid as revealed by electrophysiological methods. Proc. Natl. Acad. Sci. USA 55: 328-336.

Rakic, P. (1977) Genesis of the dorsal lateral geniculate nucleus in the rhcsus monkey: Site and time of origin, kinetics of proliferation, routes of migration and pattern of distribution of neurons. J. Comp. Neurol. 176: 23-52.

Rosenbluth, J. (1962) Subsurface cisterns and their relationship to the neuronal plasma membrane. J. Cell Biol. 13: 405-421.

Shatz, C. J. (1983) The prenatal development of the cat's retinogeniculate pathway. J. Neurosci. 3: 482-499.

Siegesmund, K. A. (1968) The fine structure of subsurface cisterns. Anat. Rec. 162: 187-196.

Silver, J. (1984) Studies on the factors that govern directionality of axonal growth in the embryonic optic nerve and at the chiasm of mice. J. Comp. Neurol. 223: 238-251.

Skoff, R. P., D. L. Price, and A. Stocks (1976) Electron microscopic autoradiographic studies of gliogenesis in rat optic nerve. I. Cell proliferation. J. Comp. Neurol. 169: 291-312.

Vaughn, D. W., and A. Peters (1974) Neuroglial cells in the cerebral cortex of rats from young adulthood to old age: An electron microscope study. J. Neurocytol. 3: 405-427.

Watanabe, H., and G. Burnstock (1976) Junctional subsurface organs in frog sympathetic ganglion cells. J. Neurocytol. 5: 125-136.

Williams, R. W., M. H. Bastiani, B. Lia, and L. M. Chalupa (1986) Growth cones, dying axons, and development fluctuations in the fiber population of the cat's optic nerve. J. Comp Neurol. 246: 32-67. 